\title{
GAMBARAN KEKUATAN, DAYA TAHAN OTOT, POWER, KELENTUKAN, KECEPATAN REAKSI, DAN DAYA TAHAN JANTUNG PARU ATLET CABANG OLAHRAGA TENIS MEJA JAWA BARAT PON XVIII/2012 RIAU BERDASARKAN STANDAR KONI PUSAT
}

\author{
Annisa Putri ${ }^{1}$, Mulya Nurmansyah Ardisasmita ${ }^{2}$ \\ ${ }^{1}$ Fakultas Kedokteran, Universitas Padjadjaran, \\ ${ }^{2}$ Departemen Ilmu Kesehatan Masyarakat, Fakultas Kedokteran, Universitas Padjadjaran,
}

\begin{abstract}
On PON XVIII/2012 Riau, achievements earned by West Java table tennis athletes were not the best. Those athletes only earned 1 silver medal and 1 bronze medal. One of several factors influencing these athlete's achievement is physical condition of the athlete. Underwhelming achievements may be caused by discrepancy of athlete's physical condition with Central KONI standards. This study aimed to describe predominant physical components of West Java table tennis athletes in PON XVIII/2012 Riau according to Central KONI standard. The study was conducted using descriptive study design and cross sectional approach using secondary data that has been measured by Sport Medicine field of KONI West Java. Secondary data consists of predominant physical components in table tennis athletes, which are strength, muscle endurance, power, flexibility, reaction speed, and heart lung strength, that will be compared to Central KONI standard. Based on Central KONI standard, there were predominant physical component of West Java table tennis athletes in PON XVIII/2012 Riau still on deficient and adequate level, which were arm and shoulder muscle strength, leg muscle strength, abdominal muscle endurance, arm muscle power, and heart lung endurance in male athletes; and arm and shoulder strength, abdominal muscle endurance, leg muscle strength, and heart lung endurance in female athletes. There were still predominant physical components of West Java table tennis athletes that have not achieved good, very good or perfect category according to Central KONI standard. Hence, efforts to coach athletes through scalable and well programmed training are needed. In conclusion, an athlete can earn gold medal if predominant physical component capability of said athlete achieved good, very good or perfect category.
\end{abstract}

Keywords: physical component, table tennis athlete, training.

Korespondensi: Annisa Putri, E-mail: annisaputri1004@yahoo.com, Departemen Anatomi, Fisiologi, dan Biologi Sel, Fakultas Kedokteran Universitas Padjadjaran. Jalan Raya Jatinangor Km 21, Sumedang, Jawa Barat, Indonesia. 


\section{PENDAHULUAN}

Kurangnya perhatian terhadap kondisi fisik atlet cabang olahraga tenis meja dapat mengakibatkan prestasi atlet kurang maksimal, baik di pertandingan nasional maupun internasional. ${ }^{1}$ Pada Pekan Olahraga Nasional (PON) XVIII/2012 yang dilaksanakan di Riau, Jawa Barat menduduki peringkat kedua dengan meraih 99 medali emas, 79 medali perak, dan 101 medali perunggu. ${ }^{6}$ Namun, cabang olahraga tenis meja Jawa Barat hanya meraih 1 medali perak dan 1 medali perunggu dari 7 nomor yang dilombakan. ${ }^{7}$ Demikian halnya pada Pesta Olahraga Asia Tenggara (SEA GAMES) XXVII/2013 yang dilaksanakan di Myanmar, cabang olahraga tenis meja Indonesia tidak meraih medali apapun. ${ }^{5}$

Terdapat tiga faktor penting agar seorang atlet dapat meraih medali emas, yaitu kondisi fisik atlet, teknik atau strategi atlet, dan kesiapan mental atlet. Prestasi puncak seorang atlet dapat dicapai oleh atlet yang berbakat dan memperoleh pembinaan baik yang dilakukan secara berjenjang dan berkesinambungan. ${ }^{2}$ Latihan jangka panjang yang progresif, dan performa yang baik dari atlet saat pertandingan dibutuhkan untuk mendapatkan medali emas dalam kejuaraan nasional maupun internasional. $^{3}$ Atlet cabang olahraga tenis meja tidak hanya membutuhkan teknik, taktik, dan kondisi psikis yang luar biasa untuk memenangkan suatu pertandingan, tetapi juga kondisi fisik yang kuat agar mampu mendapatkan prestasi yang lebih tinggi dan maksimal lagi. ${ }^{1,4}$ Perhatian terhadap pemeliharaan dan peningkatan kondisi fisik atlet cabang olahraga tenis meja penting untuk memaksimalkan prestasi atlet. ${ }^{1}$

Salah satu faktor penyebab atlet cabang olahraga tenis meja tidak berprestasi adalah kemampuan komponen fisik atlet yang rendah. Prestasi yang kurang maksimal dari atlet cabang olahraga tenis meja tersebut dimungkinkan karena adanya ketidaksesuaian kondisi fisik atlet dengan standar komponen fisik predominan Komite Olahraga Nasional Indonesia (KONI) pusat. Komponen fisik predominan yang dibutuhkan oleh atlet cabang olahraga tenis meja adalah kekuatan otot lengan dan bahu, kekuatan otot tungkai, daya tahan otot perut, daya tahan otot lengan dan bahu, daya tahan otot tungkai, power otot lengan, kelentukan, kecepatan reaksi, dan daya tahan jantung paru. ${ }^{8}$

\section{METODE PENELITIAN}

Penelitian dilakukan dari bulan Maret 2017 sampai dengan Juni 2017 dengan menggunakan desain studi deskriptif dengan pendekatan potong lintang atau cross sectional dengan sumber data sekunder yang telah diukur dan dikumpulkan oleh bidang Sport Medicine Komite Olahraga Nasional Indonesia (KONI) Jawa Barat di Jalan Padjajaran No.37A, Kota Bandung, Jawa Barat. Subjek penelitian adalah atlet putra dan putri cabang olahraga tenis meja Jawa Barat PON XVIII/2012 yang dilaksanakan di Riau. Total sampel penelitian adalah delapan atlet yang terdiri dari tiga atlet putra dan lima atlet putri cabang olahraga tenis meja Jawa Barat PON XVIII/2012 Riau.

Data penelitian didapat dari hasil pengukuran tingkat kondisi fisik atlet cabang olahraga tenis meja Jawa Barat PON XVIII/2012 Riau oleh bidang Sport Medicine KONI Jawa Barat dengan menggunakan alat ukur tertentu, yaitu kekuatan (otot lengan dan bahu, otot tungkai) dengan hand dynamometer dan leg dynamometer, daya tahan otot (otot perut, otot lengan dan bahu, otot tungkai) dengan sit ups, push ups, dan squat jumps, power (otot lengan) dengan medicine ball put, kelentukan dengan flexometer, kecepatan reaksi dengan whole body reaction, dan daya tahan jantung paru dengan Astrand test.

Hasil pengukuran tingkat kondisi fisik atlet cabang olahraga tenis meja Jawa Barat PON XVIII/2012 Riau tersebut kemudian akan dibandingkan dengan standar KONI pusat untuk diketahui kategori kemampuan komponen fisik predominannya. Standar komponen fisik predominan atlet cabang olahraga tenis meja KONI pusat adalah kemampuan komponon fisik predominan atlet - atlet yang meraih medali emas pada kejuaraan tingkat Asia atau kejuaraan tingkat internasional lainnya.

\section{HASIL PENELITIAN}

Jumlah sampel pada penelitian ini adalah delapan atlet cabang olahraga tenis meja Jawa Barat PON XVIII/2012 Riau yang terdiri dari tiga atlet putra dan lima atlet putri cabang olahraga tenis meja Jawa Barat PON XVIII/2012 Riau. 
Tabel 1. Karakteristik Fisik Atlet Cabang Olahraga Tenis Meja Jawa Barat PON XVIII/2012 Riau

\begin{tabular}{ccc}
\hline Karakteristik & Putra & Putri \\
\cline { 2 - 3 } & Rata - rata \pm SD & Rata - rata \pm SD \\
\hline Usia (tahun) & $19,7 \pm 3,1$ & $21,2 \pm 7,7$ \\
Tinggi badan $(\mathbf{c m})$ & $166,3 \pm 8,9$ & $155,0 \pm 1,3$ \\
Berat badan $(\mathbf{k g})$ & $58 \pm 3$ & $55,8 \pm 5,1$ \\
\hline
\end{tabular}

Tabel karakteristik fisik atlet cabang olahraga tenis meja Jawa Barat PON XVIII/2012 Riau menunjukkan rerata periode golden age pada atlet tenis meja Jawa Barat PON XVIII/2012 Riau, dan juga rerata berat badan dan tinggi badan pada atlet tenis meja Jawa Barat PON XVIII/2012 Riau.

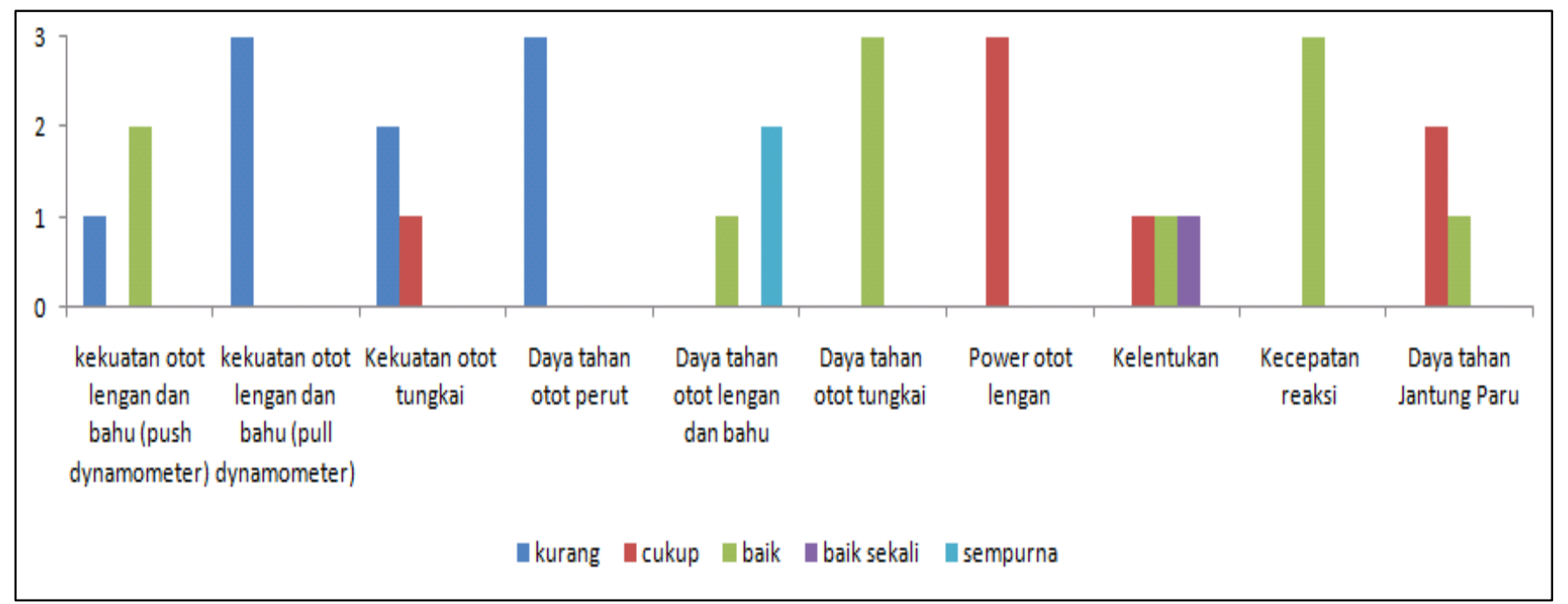

Gambar 1. Persebaran Kategori Kemampuan Komponen Fisik Predominan Atlet Cabang Olahraga Tenis Meja Jawa Barat PON XVIII/2012 Riau Berdasarkan Standar KONI Pusat (Putra)

Gambar persebaran kategori kemampuan komponen fisik predominan atlet putra cabang olahraga tenis meja Jawa Barat PON XVIII/2012 Riau berdasarkan standar KONI pusat menunjukkan kemampuan komponen kekuatan otot lengan dan bahu, kekuatan otot tungkai, daya tahan otot perut, power otot lengan, dan daya tahan jantung paru berada pada kategori kurang dan atau cukup.

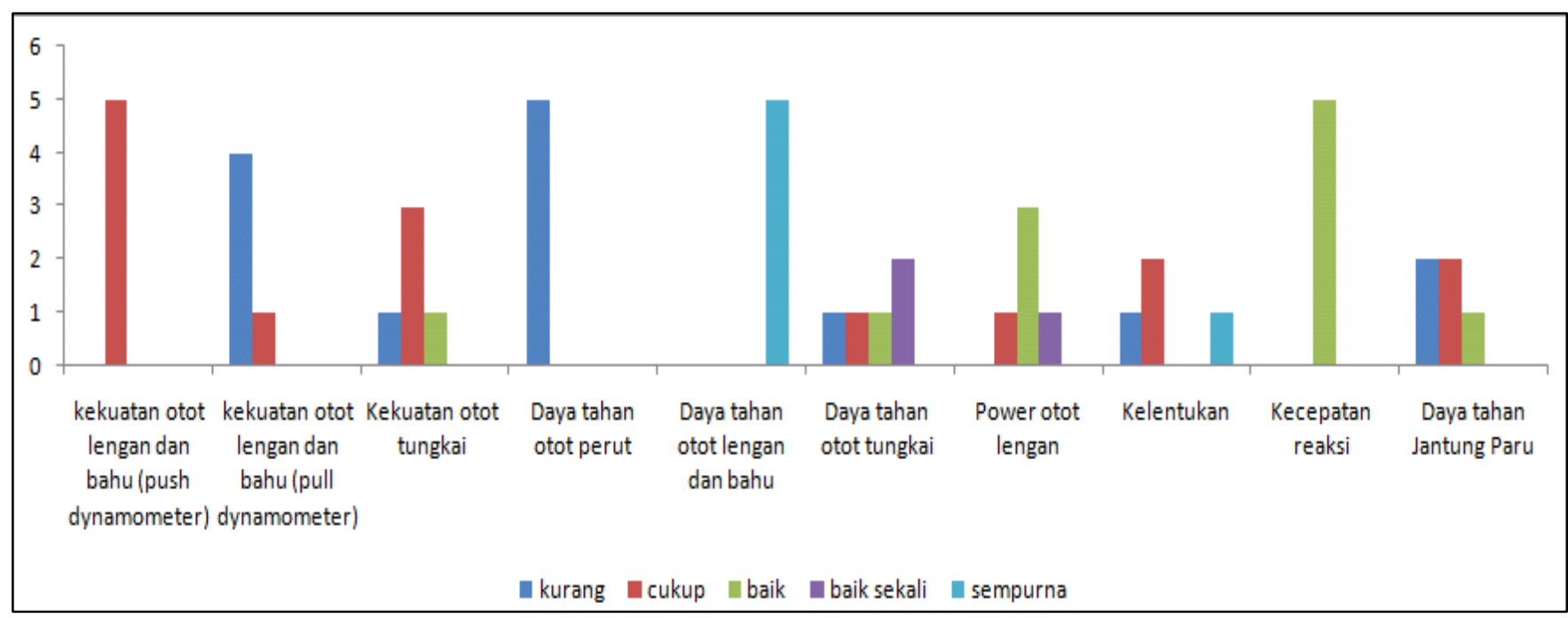

Gambar 3. Persebaran Kategori Kemampuan Komponen Fisik Predominan Atlet Cabang Olahraga Tenis Meja Jawa Barat PON XVIII/2012 Riau Berdasarkan Standar KONI Pusat (Putri) 
Gambar persebaran kategori kemampuan komponen fisik predominan atlet putri cabang olahraga tenis meja Jawa Barat PON XVIII/2012 Riau berdasarkan standar KONI pusat menunjukkan kemampuan komponen kekuatan otot lengan dan bahu, kekuatan otot tungkai, daya tahan otot perut, dan daya tahan jantung paru berada pada kategori kurang dan atau cukup.

Tabel 2. Karakteristik Kemampuan Komponen Fisik Predominan Atlet Cabang Olahraga Tenis Meja Jawa Barat PON XVIII/2012 Riau (Putra)

\begin{tabular}{llcc}
\hline Karakteristik & & Rata - rata \pm SD & Kategori \\
\hline Kekuatan & & & \\
Otot Lengan dan Bahu & $\begin{array}{l}\text { Push Dynamometer } \\
\text { Pull Dynamometer }\end{array}$ & $36,1 \pm 7,9$ & Cukup \\
Otot Tungkai & Leg Dynamometer & $17,3 \pm 10,3$ & Kurang \\
Daya Tahan Otot & & & Cukup \\
Otot Perut & Sit Ups & $21 \pm 3$ & \\
Otot Lengan dan Bahu & Push Ups & Kurang \\
Otot Tungkai & Squat Jumps & $56,7 \pm 8,7$ & Baik sekali \\
$\begin{array}{l}\text { Power } \\
\text { Otot Lengan }\end{array}$ & Medicine Ball Put & $4,4 \pm 0,8$ & Baik \\
Kelentukan & Flexometer & $14,4 \pm 6,5$ & Cukup \\
Kecepatan Reaksi & Whole Body Reaction & $0,3 \pm 0,03$ & Baik \\
Daya Tahan Jantung & Astrand test (VO2 max) & $41,3 \pm 4,9$ & Cukup \\
Paru & mL/Kg/mnt & & \\
\hline
\end{tabular}

Tabel 3. Karakteristik Kemampuan Komponen Fisik Predominan Atlet Cabang Olahraga Tenis Meja Jawa Barat PON XVIII/2012 Riau (Putri)

\begin{tabular}{llcc}
\hline Karakteristik & & Rata - rata \pm SD & Kategori \\
\hline Kekuatan & & & \\
Otot Lengan dan Bahu & Push Dynamometer & $21,6 \pm 1,5$ & Cukup \\
& $\begin{array}{l}\text { Pull Dynamometer } \\
\text { Otot Tungkai }\end{array}$ & $16,2 \pm 3,8$ & Kurang \\
Daya Tahan Otot & & $79,1 \pm 48,6$ & Cukup \\
Otot Perut & Sit Ups & $10,6 \pm 9,8$ & Kurang \\
Otot Lengan dan Bahu & Push Ups & $23 \pm 4,2$ & Sempurna \\
Otot Tungkai & Squat Jumps & $33,8 \pm 20,7$ & Baik \\
Power & & & \\
Otot Lengan & Medicine Ball Put & $3,8 \pm 0,4$ & Baik sekali \\
Kelentukan & Flexometer & $16,5 \pm 16,9$ & Baik \\
Kecepatan Reaksi & Whole Body Reaction & $0,3 \pm 0,02$ & Baik \\
Daya Tahan Jantung & Astrand test $\left(\mathrm{VO}_{2}\right.$ max) & $33,4 \pm 7,4$ & Cukup \\
Paru & mL/Kg/menit & & \\
\hline
\end{tabular}


Berdasarkan tabel karakteristik kemampuan komponen fisik predominan atlet putra cabang olahraga tenis meja Jawa Barat PON XVIII/2012 Riau, kemampuan komponen kekuatan otot lengan dan bahu, kekuatan otot tungkai, daya tahan otot perut, power otot lengan, dan daya tahan jantung paru belum berada pada kategori baik atau baik sekali.

Berdasarkan tabel karakteristik kemampuan komponen fisik predominan atlet putri cabang olahraga tenis meja Jawa Barat PON XVIII/2012 Riau, kemampuan komponen kekuatan otot lengan dan bahu, kekuatan otot tungkai, daya tahan otot perut, dan daya tahan jantung paru belum berada pada kategori baik, baik sekali atau sempurna.

\section{DISKUSI}

Komponen fisik predominan yang dibutuhkan oleh atlet cabang olahraga tenis meja meliputi, kekuatan otot lengan dan bahu, kekuatan otot tungkai, daya tahan otot perut, daya tahan otot lengan dan bahu, daya tahan otot tungkai, power otot lengan, kelentukan, kecepatan reaksi, dan daya tahan jantung paru. ${ }^{9,8}$

Daya tahan jantung paru yang baik sangat dibutuhkan oleh atlet cabang olahraga tenis meja karena tenis meja merupakan aktivitas predominan anaerobik yang membutuhkan tingkat pengkondisian aerobik yang tinggi untuk menghindari kelelahan dan membantu pemulihan. ${ }^{11}$ Dari hasil penelitian didapatkan bahwa komponen kondisi fisik predominan atlet putra dan putri cabang olahraga tenis meja Jawa Barat PON XVIII/2012 Riau yaitu daya tahan jantung paru berdasarkan standar KONI pusat berada pada kategori cukup.

Fleksibilitas pergelangan tangan yang baik pada atlet cabang olahraga tenis meja akan memberikan kemampuan untuk melakukan pergerakan sendi dari berbagai arah untuk melakukan berbagai jenis pukulan, baik backhand maupun forehand, sehingga bola akan menjadi lebih mudah dikontrol dan ketika akan mematikan lawan dengan spin, putaran bola akan menjadi lebih kencang sehingga lawan sulit untuk mengembalikannya lagi. Atlet cabang olahraga tenis meja juga membutuhkan fleksibilitas pinggul yang baik untuk membantu gerakan memukul pada saat back swing dan forward swing, sehingga pukulan ke arah lawan bisa maksimal dan dapat terhindar dari cedera. ${ }^{1}$ Dari hasil penelitian didapatkan bahwa komponen kondisi fisik predominan atlet putra dan putri cabang olahraga tenis meja Jawa Barat PON XVIII/2012 Riau yaitu fleksibilitas berdasarkan standar KONI pusat berada pada kategori baik.
Daya tahan otot yang baik sangat dibutuhkan oleh atlet cabang olahraga tenis meja karena daya tahan otot akan mempertahankan pukulan kuat yang berulang dan gerakan cepat di lapangan. ${ }^{4,10}$ Pukulan pada permainan tenis meja harus dilakukan dengan kecepatan dan kekuatan otot yang besar agar pukulan dapat dilakukan secara maksimal sehingga lawan sulit untuk mengembalikan bola. ${ }^{1}$ Perpindahan dan perubahan arah atlet cabang olahraga tenis meja yang cepat selama pertandingan membutuhkan power otot lengan yang cepat dan kuat. ${ }^{1,4}$ Dari hasil penelitian didapatkan bahwa komponen kondisi fisik predominan atlet putra dan putri cabang olahraga tenis meja Jawa Barat PON XVIII/2012 Riau yaitu daya tahan otot perut berdasarkan standar KONI pusat berada pada kategori kurang, daya tahan otot lengan dan bahu berada pada kategori baik sekali dan sempurna, dan daya tahan otot tungkai berada pada kategori baik. Kekuatan otot lengan dan bahu atlet putra dan putri cabang olahraga tenis meja Jawa Barat PON XVIII/2012 Riau berdasarkan standar KONI pusat berada pada kategori cukup pada tingkat pengukuran push dynamometer dan berada pada kategori kurang pada tingkat pengukuran pull dynamometer dan kekuatan otot tungkai berada pada kategori cukup. Komponen kondisi fisik predominan atlet putra cabang olahraga tenis meja Jawa Barat PON XVIII/2012 Riau yaitu power otot lengan berdasarkan standar KONI pusat berada pada kategori cukup, sedangkan pada atlet putri berada pada kategori baik sekali.

Selain itu, atlet cabang olahraga tenis meja harus memiliki waktu reaksi yang cepat agar dapat menerima dan mengembalikan bola lawan secara tepat karena permainan tenis meja merupakan permainan dengan tempo yang cepat. ${ }^{1}$ Dari hasil penelitian didapatkan bahwa komponen kondisi fisik predominan atlet putra dan putri cabang olahraga tenis meja Jawa Barat PON XVIII/2012 Riau yaitu kecepatan reaksi berdasarkan standar KONI pusat berada pada kategori baik.

Masih adanya komponen fisik predominan atlet cabang olahraga tenis meja Jawa Barat PON VXIII/2012 Riau yang belum mencapai kategori baik, baik sekali atau sempurna berdasarkan standar KONI pusat tersebut menjadi salah satu faktor kurang maksimalnya prestasi atlet cabang olahraga tenis meja Jawa Barat. Pembinaan atlet secara berjenjang dan berkesinambungan melalui program latihan yang terukur dan terprogram dengan baik dapat membantu meningkatkan kondisi fisik seorang atlet sehingga dapat tampil dengan baik saat pertandingan. 
Penelitian selanjutnya diharapkan dapat mempertimbangkan faktor lain selain kondisi fisik yang dapat mempengaruhi prestasi seorang atlet karena prestasi seorang atlet tidak hanya ditentukan oleh kemampuan kondisi fisiknya, tetapi juga oleh teknik atau strategi dan kesiapan mental atlet.

\section{KESIMPULAN}

Masih terdapat komponen fisik predominan atlet cabang olahraga tenis meja Jawa Barat PON XVIII/2012 Riau yang belum mencapai kategori baik, baik sekali atau sempurna berdasarkan standar KONI pusat. Pada atlet putra, komponen kekuatan otot lengan dan bahu (pull dynamometer) dan daya tahan otot perut berada pada kategori kurang, komponen kekuatan otot lengan dan bahu (push dynamometer), kekuatan otot tungkai, power otot lengan, dan daya tahan jantung paru berada pada kategori cukup. Pada atlet putri, komponen kekuatan otot lengan dan bahu (pull dynamometer) dan daya tahan otot perut berada pada kategori kurang, komponen kekuatan otot lengan dan bahu (push dynamometer), kekuatan otot tungkai, dan daya tahan jantung paru berada pada kategori cukup.

Oleh karena itu, kemampuan komponen fisik predominan atlet cabang olahraga tenis meja masih perlu ditingkatkan lagi dalam bentuk pembinaan atlet secara berjenjang dan berkesinambungan melalui pelatihan yang terukur dan terprogram dengan baik. Beberapa cara untuk meningkatkan kemampuan komponen fisik predominan pada atlet cabang olahraga tenis meja, antara lain melakukan latihan beban, peregangan kontraksi relaksasi, pemahaman kemampuan motorik, latihan anaerob laktasid, dan latihan speed play.

\section{UCAPAN TERIMA KASIH}

Penulis mengucapkan terima kasih kepada Prof. Dr. Ambrosius Purba, dr., AIFO., M.S. dan Mulya Nurmansyah Ardisasmita, dr., M.T. atas waktu dan bimbingan serta masukan dan saran selama penelitian dan penulisan kepada penulis sehingga artikel jurnal ini dapat terselesaikan.

\section{DAFTAR PUSTAKA}

1. Mahendra IR, Sugiyanto PD, Kiyatno. Faktor Kondisi Fisik Dominan Penentu Prestasi Bermain Tenis Meja. Sport Sci, 2014;1(1):1-13.

2. Purba, A. 2016. Penerapan Faal Olahraga untuk Prestasi Atlet, Asupan Gizi, Penatalaksanaan Cedera Olahraga Taping. Bandung: Universitas Padjadjaran. hal 2.

3. Tønnessen E, Sylta Ø, Haugen TA, Hem E, Svendsen IS SS. The Road to Gold: Training and Peaking Characteristics in the Year Prior to a Gold Medal Endurance Performance. PLoS One. 2014;9(7):15-7.

4. Pradas, F., Carrasco, L., Floria, P. Muscular Power of Leg Extensor Muscles in Young Toplevel Table Tennis Players. Internat $J$ of Table Tennis Sci. 2010;6:178-180.

5. Situmorang HD. 2015. Raih Perunggu SEA Games, Tenis Meja Bangga. [diunduh pada 2 Desember 2017]. Tersedia dari: http://www.beritasatu.com/olahraga/281214raih-perunggu-sea-games-tenis-mejabangga.html.

6. Ucu, KR. 2012. Daftar Akhir Perolehan Medali PON Riau 2012. [diunduh pada 2 Desember 2017]. Tersedia http://www.republika.co.id/berita/olahraga/peka n-olahraga-nasional/12/09/20/manp26-daftarakhir-perolehan-medali-pon-riau-dki-juaraumum

7. Wikipedia. Tenis Meja pada Pekan Olahraga Nasional XVIII 2012. [diunduh pada 2 Desember 2017]. Tersedia dari: https://id.wikipedia.org/wiki/Tenis_Meja_pada_ Pekan_Olahraga_Nasional_XVIII .

8. Purba, A. 2014. Prosedur Pelaksanaan Tes Kondisi Fisik/Tes Fisiologi Atlet. Bandung: Perhimpunan Ahli Ilmu Faal Olahraga Indonesia (PAIFORI).

9. Putra J, Nuzuli, Masri. Hubungan Power Otot Lengan dengan Keterampilan Bermain Tenis Meja pada Klub Atlet Indonesia Muda Tahun 2013. J Ilmu Mhs Pendidik Jasmani, Kesehat dan Rekreasi. 2015;1(2):91-101.

10. Kondrič M, Zagatto AM, Sekulić D. The physiological demands of table tennis: A review. J Sport Sci Med. 2013;12(3):362-70.

11. Behdarİ R, Ahadİ $M$, Husseİnİ $M$, Göktepe $M$. Comparison and Description of Fitness Level, Physiological and Anthropometric Profiles of Selected Versus Non Selected Iranian National Team Table Tennis Players. Int J Sci Cult Sport. 2015;(4):371-82. 